\title{
Childhood Middle Ear Tuberculosis-A Rare Case Report
}

Swain PK ${ }^{1}$, Mallik SA ${ }^{2}$, Thapalial $\mathrm{A}^{3}$

${ }^{1}$ Dr. PK Swain M.D. Paediatrics, Associate Professor, ${ }^{2}$ Dr. SA Mallik, M.S. ENT. Assistant Professor, Ear,Nose \& Throat. ${ }^{3}$ Dr. Anna Thapalial, M.D. Paediatrics Professor \& HOD Pediatrics Manipal College of Medical Sciences(MCOMS), Phulbari, Pokhara, Nepal.

Address for Correspondence: Dr. Pradipta Kumar Swain

E-mail: pkswain1@rediffmail.com

\begin{abstract}
Tuberculosis rarely affects the middle ear cleft; the disease is a curiosity and not often considered in the differential diagnosis of otorrhea. The diagnosis is thus made too late, with resulting complications such as irreversible hearing loss and facial nerve paralysis. A case report with review of the literature is presented, emphasizing that tuberculosis should be considered in the differential diagnosis of chronic ear infection in children. In our case direct nosocomial spread of tuebrculous bacilli has been attributed.
\end{abstract}

Key words: Tuberculosis; otitis media, hearing loss \& facial paralysis.

\section{Introduction}

Tuberculosis affects middle ear rarely. It is difficult to assess its true incidence as the large reported series has been selected from hospitalized sub-groups with established tuberculosis ${ }^{1}$. These patient usually present with unexpectedly severe hearing loss, facial palsy, past history of tuberculosis, presence of pale abundant granulation with normal mastoid cellular development. We are reporting an apparently healthy child who had otorrhoea but was found to be middle ear tuberculosis, with hearing loss \& without CNS involvement.

\section{Case Report}

A 7year old male resident of Rigna Raha-2 Attindada, Palpa, Nepal, presented with complaints of left ear discharge on and off since 2 years. Initially there was pain in the left year for 2-3 days followed after a week by purulent $\&$ foul smelling ear discharge lasting for 4-5 weeks which subsided after being treated with ear drops and oral medication in Palpa local hospital. Despite treatment scanty ear discharge was still persisting since last 2 years for which the child was referred to Manipal College of Medical Sciences (Manipal Teaching Hospital) Nepal (MCOMS). When the patient first reported to MCOMS he had complained of active purulent foul smelling blood stained ear discharge without any pain or fever but with hearing loss for last 2 months. There was history suggestive of no weight gain since last 9 months but no history of contact with tuberculosis.

Fig 1: Showing Active Purulent Discharge from the Ear.

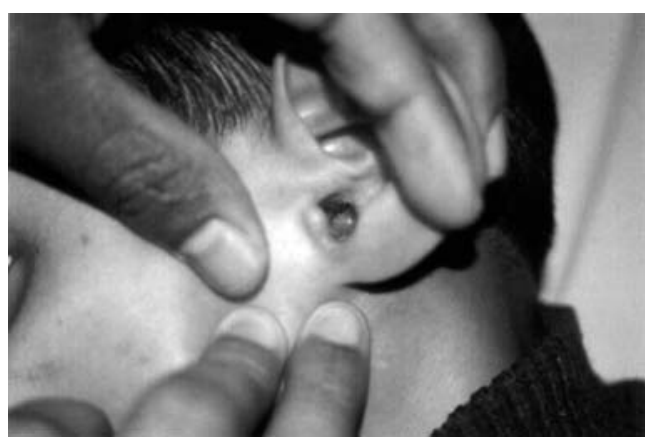

Examination revealed active purulent discharge, which on cleaning revealed pale looking granulomatous tissue, with a tendency to bleed on touch. The granulation tissue was cauterized with $10 \%$ Silver Nitrate (AgN03) and the patient was sent on gentamycin ear drop and tab cefadroxil. There was no significant cervical/axillary lymphadenopathy. Following investigations were done in view of the chronicity of symptoms like weight loss \& non-healing ear infection. $\mathrm{Hb}-11.7 \mathrm{gm} \%$, TLC-9000/cmm, ESR-3mm/1hr, DC-N-54, L-45,E-1,M-0, X-ray chest showed Hilar prominence with increased bronchovascular markings, X-ray left mastoid showed increased air space. Mantoux test was $9 \mathrm{~mm}$ after 48 hours. Culture of the ear discharge showed scanty growth of enterococcus species. Z-N staining of discharge showed acid fast bacilli in 2 samples out of 3. Biopsy of granulation tissue was conclusive. Audiometry revealed moderate conductive hearing loss in left ear. Contrast enhanced CT scan brain showed no intracranial abnormality. Axial section of the temporal bone showed non-enhancing tissue in external ear with bony communication to left side mastoid air cells cavity. Left side mastoid air cells were under developed.

In view of apparent weight loss \& presence of AFB in the ear discharge this child was started on anti-tubercular treatment (DOTS category-I). The patient is responding well to the treatment with decrease in the ear discharge and size of the granulation tissue.

\section{Discussion}

Middle ear tuberculosis is known to occur in all ages, $50 \%$ of which is in children. About half of these cases usually present with painless otorrhea, often of long duration. Tuberculous otitis media (TOM) is uncommon in developed countries. This condition is associated with significant sequelae including development of profound and permanent hearing $\operatorname{loss}^{2} .9 .5 \%$ of children with tuberculous otitis media were $<5$ years of age in a study conducted by Kirsch C.M.et all ${ }^{3}$.

Our patient presented with classic symptoms of otitis media related to tuberculosis: painless draining ears; profuse 
granulation tissue on otoscopic examination; and significant hearing loss. Hutton M.D. et all in 1990 described nosocomial transmission of tuberculosis with draining abscess ${ }^{4}$. Our patient had chronic draining of left ear for 2 years. Duration of actual symptoms varies from weeks to 40 years ${ }^{5}$. Our patient's chest radiograph showed Hilar prominence, a relatively typical finding in children, which cannot be taken as an exclusive evidence of primary pulmonary tuberculosis. Concomitant pulmonary tuberculosis should suggest the aetiology in a patient with chronic otitis media; however, tuberculous otitis media cannot be excluded when otorrhea occurs in a patient without pulmonary disease. Nosocomial transmission of tuberculous bacilli on a draining abscess may be a better option in this case especially when ESR is not raised \& Mantoux test is doubtful (with BCG scar).

The pathogenesis of tuberculous otitis media is likely related to three distinct mechanisms: spread to the middle ear via the Eustachian tube; hematogenous spread from another tuberculous focus and rarely, direct implantation through the external auditory canal and a tympanic membrane perforation. The most frequent complication is hearing loss, which may be profound. Generally tuberculosis of the middle ear is unilateral.The most common complication next to hearing loss is facial nerve paralysis ( $24 \%$ to $39 \%$ ). Facial nerve paralysis has been reported in cases of TOM even after starting treatment, so starting of treatment is not an assurance that the patient will not develop complications later $\&$ hence should be followed up periodically The advent $\&$ availability of specific chemotherapy has changed all this \& today surgery should be reserved for decompression of the facial nerve \& removal of necrotic material which might provide a nidus for the organism to remain out of reach of anti tuberculous therapy.

Tuberculous otitis media is an uncommon disease, a rare direct implantation pathogenesis has been attributed to this case. If left untreated, it causes great damage to the middle ear \& the surrounding tissues. Early diagnosis \& treatment offers good prospect of eventless healing.

\section{References}

1. Windle Tayloi PC, Bailey CM.Tuberculosis Otitis Media.Laryngoscope; 1980: 90,1039.

2. Craig DH. Tuberculous Mastoiditis: A Review Of Eight Cases. J Laryngol Otol 1962; 76: 623-38.

3. Kirsch CM, Wehner JH, Jensen WA, Kagawa FT, Campagna AC. Tuberculous Otitis Media. South Med J 1995; 88: 363-6.

4. Hutton MD, Stead WW, Cauthen GM, Bloch AB, Ewing WM. Nosocomial Transmission Of Tuberculosis Associated With A Draining Abscess. J Infect Dis 1990; 16: 286-95.

5. Plester D, Pusalkar A, Steinbach E. Clinical Records: Middle Ear Tuberculosis. J Laryngol Otol 1980; 94: 1415-21. 